\title{
Reflets
}

Revue ontaroise d'intervention sociale et communautaire

\section{Les handicapés mentaux : un sujet tabou}

\section{Fleur-Ange Rancourt}

Volume 4, numéro 2, automne 1998

Personnes vivant avec une incapacité

URI : https://id.erudit.org/iderudit/026230ar

DOI : https://doi.org/10.7202/026230ar

Aller au sommaire du numéro

Éditeur(s)

Reflets : Revue ontaroise d'intervention sociale et communautaire

ISSN

1203-4576 (imprimé)

1712-8498 (numérique)

Découvrir la revue

Citer ce document

Rancourt, F.-A. (1998). Les handicapés mentaux : un sujet tabou. Reflets, 4(2),

176-178. https://doi.org/10.7202/026230ar

Tous droits réservés (C) Reflets : Revue ontaroise d'intervention sociale et communautaire, 1998

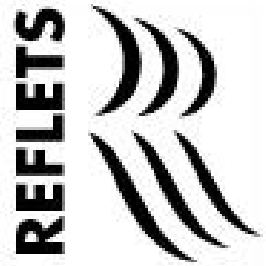

Ce document est protégé par la loi sur le droit d'auteur. L'utilisation des services d'Érudit (y compris la reproduction) est assujettie à sa politique d'utilisation que vous pouvez consulter en ligne.

https://apropos.erudit.org/fr/usagers/politique-dutilisation/ 


\section{Les handicapés mentaux : un sujet tabou}

Fleur-Ange Rancourt, Sudbury

Le handicapé n'est pas un malade, il est différent. Les personnes qui sont affligées d'un handicap mental ne le sont pas toutes lorsqu'elles viennent au monde. Plusieurs subissent des accidents à la naissance, d'autres sont atteintes d'une maladie en bas âge et deviennent handicapés pour la vie.

J'ai une enfant handicapée. En fait, la dernière de mes quatorze enfants, Carmen, est née différente des autres. À la naissance, son visage s'est présenté d'abord et sa glande thyroïde a été, en partie, écrasée. Son cerveau est resté plus petit que la normale. Le médecin a parlé de microcéphale, c'est-à-dire, selon le dictionnaire, qui a une tête anormalement petite, accompagné d'un débile mental moyen.

Nous, parents, n'avons jamais suivi de cours pour apprendre comment éduquer une enfant dite «anormale». D'habitude, à sept ou huit mois, l'enfant commence à se traîner puis, vers onze ou douze mois, elle est capable de marcher. Carmen a marché à deux ans et demi. Elle a porté des couches jusqu'à l'âge de cinq ans. À deux ans, elle mangeait encore de la nourriture de bébé. Elle s'étouffait avec un petit grain de riz et elle ne tenait pas son biberon.

Nous nous posions des questions. Qu'est-ce qui est le plus important pour le bien de Carmen? Serait-elle mieux avec des gens comme elle? Elle sait bien qu'elle n'est pas comme les autres, du moins, elle le sentait. 
Si nous la gardions avec nous sans rien lui apprendre, nous courrions à la catastrophe. Carmen avait besoin d'apprendre très tôt tout ce qu'elle pouvait, de développer son potentiel au maximum. Cela ne pouvait se faire qu'avec l'aide de personnes compétentes. Et à Noëlville, il n'existait pas d'école pour elle.

Il nous fut suggéré de la placer à Smith Falls, près d'Ottawa. En 1966, elle n'avait que sept ans quand, croyant bien faire, nous sommes allés la reconduire dans cette institution. Pauvre petite! Elle ne savait pas où elle allait. Comme c'était difficile de laisser notre bébé aux mains d'étrangers!

En 1964, en France, la maison de l'Arche venait d'être fondée par Jean Vanier. On ne connaissait pas Jean Vanier, mais il allait parfois à Ottawa donner des conférences. Certains de nos enfants allaient à l'université et l'ont entendu parler de cette maison pour personnes handicapées.

En 1972, nous avons quitté Noëlville et nous sommes déménagés à Ottawa. Une fois par mois, nous allions chercher Carmen. Chaque fois qu'elle devait retourner à Smith Falls, elle faisait une crise. Elle aimait mieux être avec les siens. Nous trouvions bien difficile de nous séparer de notre enfant. Mais cette solution nous semblait la meilleure solution à l'époque.

À un moment donné, nous avons appris que l'institution où demeurait Carmen, voulait diminuer le nombre de ses résidants. Il y en avait 2400 . Nous avons sauté sur l'occasion et nous avons repris notre fille. Elle avait alors quatorze ans.

Entre-temps, Nicole et mon fils Paul ont ouvert un foyer de l'Arche, nommé Le Printemps, à St-Malachie au Québec. Mon mari et moi sommes allés passer Noël à cette Arche avec Carmen. Elle s'y est vite plu et s'est liée d'amitié avec Diane, une fille qui demeurait là. Elles ne parlaient pas beaucoup, mais elles riaient et avaient du plaisir ensemble. Elles se comprenaient.

En 1976, après la mort de mon mari, je suis déménagée à l'Arche. J'ai demandé qu'on y accueille Carmen, même si elle était ontarienne. À ma grande joie, on l'a fait.

Comme parent, je trouve que l'Arche est le meilleur endroit pour une personne handicapée. Les résidants, comme on appelle 
les personnes handicapées qui y demeurent, se sentent aimés et acceptés. Ils peuvent communiquer entre eux et même ceux qui parlent à peine peuvent se faire comprendre.

Pour travailler à l'Arche, les assistants chargés de prendre soin des personnes handicapées, doivent les aimer. Sinon, ils ne restent pas longtemps. À l'Arche, nous ne sommes pas chez nous, mais chez eux. Si on n'aime pas demeurer ici, on déménage, mais pas eux. Ils n'ont pas grand place dans le monde.

Comme JeanVanier le dit dans la Charte internationale de l'Arche:

La communauté de l'Arche cherche à atteindre une plus grande maturité chez ses membres. Nous assistons à une solidarité de plus en plus réelle. Il y a chez nous une interpellation à l'engagement, où chacun participant à sa croissance, participe également à celles des autres en apprenant à apprivoiser nos peurs: peur de l'échec, peur du ridicule, peur de la souffrance, peur de l'autre, de ce qu'elles nous révètent de nos propres faiblesses, peur des exigences et de la vérité d'aimer et d'être aimé. Ces communautés veulent être des communautés d'espérance où tous cherchent à progresser et à réaliser leurs aspirations humaines et spirituelles pour atteindre toute l'autonomie de la vie et du travail dont ils sont capables. Nous sommes tous handicapés, pour certains le handicap est plus extérieur, pour d'autres, plus intérieur (insécurité, égoïsme, orgueil, peur, etc.).

J'ai beaucoup parlé de ma fille. Chaque parent pourrait en faire autant lorsqu'il s'agit de leur enfant. Je suis contente que Carmen soit à l'Arche. Je m'en aperçois davantage parce que je vieillis. Je trouve ça difficile de m'occuper d'elle. Elle ne pourrait pas demeurer toujours avec moi à Hanmer, car je la traiterais comme mon éternel bébé. Il faut qu'elle grandisse, mais il faudra toujours lui aider à prendre son bain, à se laver les cheveux, à couper sa viande. Il faudra lui dire de se laver les mains, de les essuyer, etc. Si je meurs avant elle, ses frères et sœurs continueront d'aller la visiter, mais elle est chez elle à l'Arche pour le reste de sa vie. 